International Journal of Engineering \& Technology, $7(3.2)(2018)$ 783-785
International Journal of Engineering \& Technology
SPC
Website: www.sciencepubco.com/index.php/IJET
Research paper

\title{
Application of Data Encryption Standard and Lempel-Ziv-Welch Algorithm for File Security
}

Ida Bagus Ary Indra Iswara ${ }^{1}$, I Ketut Sudarsana ${ }^{2}$, Nurlaidy Joice Simamora ${ }^{3}$, Vivi Novalia Sitinjak ${ }^{3}$, Nurhayati Purba $^{3}$, Citra Kurniawan ${ }^{4}$, Nurul Aziza ${ }^{5}$, Dheasy Herawati ${ }^{5}$, Dian Rianita ${ }^{6}$, Hengki Mangiring Parulian Simarmata $^{7}$, Elita Modesta Br Sembiring ${ }^{3}$, Ari Riswanto ${ }^{8}$, Rosida Tiurma Manurung, , Sofwan Hadi ${ }^{10}$, M Mesiono ${ }^{11}$, Andysah Putera Utama Siahaan ${ }^{12}$, Wirda Fitriani ${ }^{12}$, Diana Suita ${ }^{13}$, Ramadhona Simbolon ${ }^{14}$, Robbi Rahim ${ }^{15^{*}}$

\author{
${ }^{1}$ STMIK STIKOM Indonesia, Denpasar, Indonesia \\ ${ }^{2}$ Institut Hindu Dharma Negeri, Denpasar, Indonesia \\ ${ }^{3}$ Universitas Methodist Indonesia, Medan, Indonesia \\ ${ }^{4}$ Department of Electrical Engineering, Sekolah Tinggi Teknik Malang, Indonesia. \\ ${ }^{5}$ Universitas Maarif Hasyim latif, Sidoarjo, Indonesia \\ ${ }^{6}$ Universitas Lancang Kuning, Pekanbaru, Indonesia \\ ${ }^{7}$ Politeknik Bisnis Indonesia, Indonesia \\ ${ }^{8}$ Economic Education and Management, STKIP PGRI Sukabumi, Indonesia \\ ${ }^{9}$ Graduate Program in Scientific Psychology, Universitas Kristen Maranatha, Bandung, Indonesia \\ ${ }^{10}$ IAIN Ponorogo, Indonesia \\ ${ }^{11}$ Universitas Islam Negeri Sumatera Utara, Medan, Indonesia \\ ${ }^{12}$ Universitas Pembangunan Pancabudi, Medan, Indonesia \\ ${ }^{13}$ Universitas Harapan Medan, Medan, Indonesia \\ ${ }^{14}$ Universitas Islam Sumatera Utara, Medan, Indonesia \\ ${ }^{15}$ Sekolah Tinggi Ilmu Manajemen Sukma, Medan, Indonesia \\ *Corresponding author E-mail: usurobbi85@zoho.com
}

\begin{abstract}
The security and speed of data transmission is very important in data communications, the steps that can be done is to use the appropriate cryptographic and compression algorithms in this case is the Data Encryption Standard and Lempel-Ziv-Welch algorithms combined to get the data safe and also the results good compression so that the transmission process can run properly, safely and quickly
\end{abstract}

Keywords: Security, Data Transmission, Data Encryption Standard, Lempel-Ziv-Welch

\section{Introduction}

Security and confidentiality issues are an important aspect of data, messages and information[1]-[5]. Delivery of a message, data and information of great importance requires a high level of security. With the development of today information is so fast where everyone will be easy to get a message, data and information, it make various ways people do to get the data and information[6]-[11] Starting from the easy level to the more complicated ways, and many people also try to protect the message so that it cannot be known by people who do not have rights to the message or data[12]-[16].

Addition to the process of securing the data or information also needs to be done the process of measuring the size of a data (Compression)[17], [18]. The purpose of this compression is to speed up the transmission of data or information[19]. Data compression also aims to reduce the size of data and can be stored on storage media that has a relatively small size. Security and speed are important in communication using computers and computer networks[20], [21].
Data Encryption Standard (DES) algorithm are one of the most widely used encryption algorithm in the world[9], [22]. In general, the data encryption standard is divided into three groups, namely key processing, 64 bit encryption and 64 bit data description in which each group will interact with each other. Because DES algorithm has been widely used then here the authors will do a merger of the DES algorithm and LZW algorithm[20], [23], so that the level of security obtained higher and expected data or information cannot be read easily by irresponsible parties.

\section{Methodology}

\section{A. Cryptography}

Cryptography has an important role in the world of computers. This is caused because the number of confidential information that is stored and sent through computer media[24], [25]. This information usually contains document documents important financial 
data from an agency that do not want to be read by unauthorized person on the information.

In general, Cryptography is an information security technique that is done by processing plaintext by using a certain encryption algorithm and producing ciphertext that cannot be read directly.

Cryptography has a very long and amazing history. Most of the history of Cryptography is part of classical cryptography, which is a cryptographic method that uses paper and pencil or uses simple mechanical aids to date that already use mathematical calculations like the DES (Data Encryption Standard) algorithm.

DES is a block cipher algorithm that belongs to a cryptographic system of symmetry[26]. DES operates on a 64 bit block size. DES encrypts 64 bits of plaintext into 64 bit ciphertext using 56 bits of internal keys. The internal keys on the DES Algorithm are generated from external keys that are 64 bits long[27]

\section{B. Compression}

Data compression is the science or art of representing information in a more compact form. The purpose of data compression is to represent a digital data with as few bits as possible, but retain the minimum requirement to reshape the original data (decompression) [28]

The Lempel-Ziv-Welch (LZW) algorithm, developed by Abraham Lempel, Jacob Ziv, and Terry Welch. This algorithm reduces the number of tokens required to 1 symbol only[23], [28]. This symbol refers to the index in the dictionary, LZW fills this dictionary with all required alphabet symbols. In the general case, the first 256 index of the dictionary will be filled with ASCII characters from 0-255. Because the dictionary has been filled with all possible characters first, the first input character will always be found in the dictionary. This is why the token in LZW requires only 1 symbol which is a pointer to the dictionary.

\section{Results and Discussion}

Application of file security by implement DES and LZW algorithm is made by using Embarcadero Delphi XE5 programming language with windows operating system 1064 bit, here is the result of testing perform.

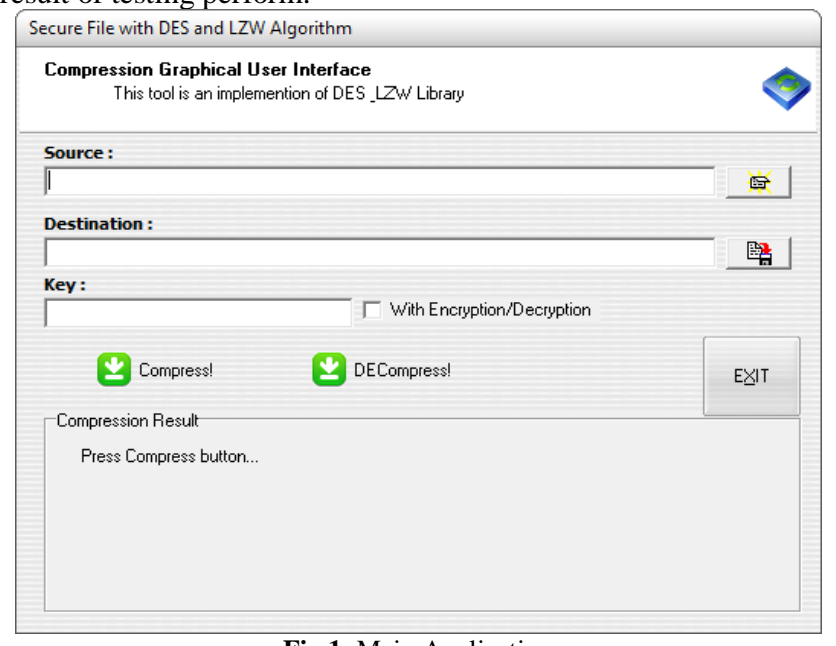

Fig 1. Main Application

Experiment were performed on several document files of different sizes with non-cryptographic DES testing as well as with the DES algorithm, figure 2 and 3 are the result experiment.

Table 1. Encryption and Compression Result

\begin{tabular}{|c|l|c|c|c|}
\hline No & Filename & Original (KB) & Compress(KB) & Ratio \\
\hline 1 & Chapter_1.doc & 1587 & 1412 & $11.03 \%$ \\
\hline 2 & MOA.txt & 78 & 17 & $78.20 \%$ \\
\hline 3 & License.txt & 30 & 5 & $83.33 \%$ \\
\hline 4 & Full_theses.docx & 6712 & 5390 & $19.69 \%$ \\
\hline 5 & Order.txt & 104 & 29 & $72.11 \%$ \\
\hline
\end{tabular}

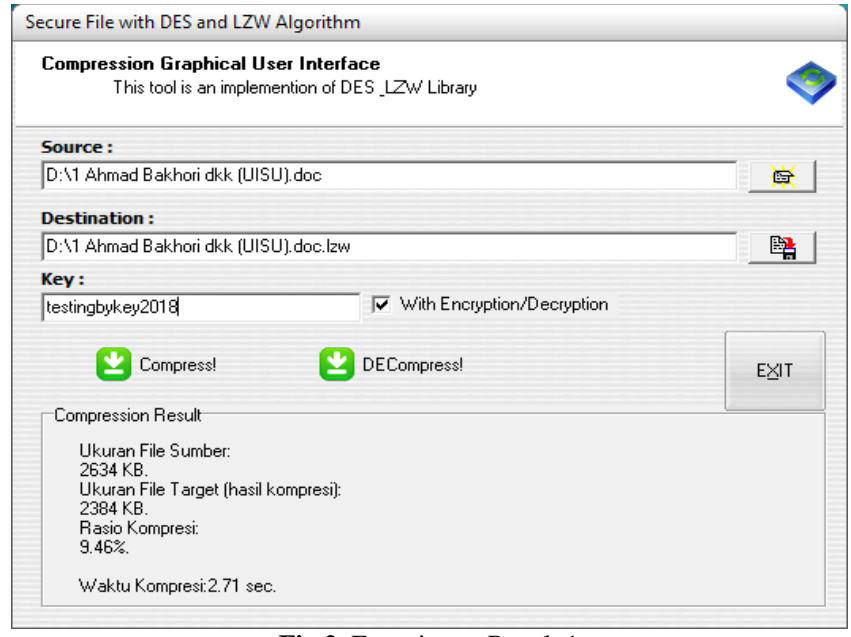

Fig 2. Experiment Result 1

\begin{tabular}{|c|c|}
\hline \multicolumn{2}{|l|}{ Secure File with DES and LZW Algorithm } \\
\hline \multicolumn{2}{|l|}{$\begin{array}{l}\text { Lompression Graphical U ser Interface } \\
\text { This tool is an implemention of DES _LW L Library }\end{array}$} \\
\hline \multicolumn{2}{|l|}{ Source: } \\
\hline D:tsample DESLZW:txt & E \\
\hline \multicolumn{2}{|l|}{ Destination : } \\
\hline D:Ssample DESLZW:tyt. Izw & 駡 \\
\hline \multicolumn{2}{|l|}{ Key: } \\
\hline$\sqrt{\nabla}$ With Encryption/Decryption & $\sqrt{\checkmark}$ With Encryption/Decryption \\
\hline 1 Compress! $\quad 1$ DECompress! & EXIT \\
\hline \multicolumn{2}{|l|}{ Compression Result } \\
\hline \multicolumn{2}{|l|}{$\begin{array}{l}\text { Ukuran File Sumber: } \\
16 \mathrm{~KB} \text {. } \\
\text { Ukuran File Target (hasil kompresi): } \\
6 \mathrm{~KB} \text {. } \\
\text { Rasio Kompresi: } \\
63.10 \%\end{array}$} \\
\hline Waktu Kompresi: $1.85 \mathrm{sec}$. & \\
\hline
\end{tabular}

Fig 3. Experiment Result 2

Figures 2 and 3 are examples of file security testing using DES algorithm and also compression process using LZW algorithm, testing is done on 2 different files with different sizes but on the results obtained different result which in the file of ratio of security and compression of $9.46 \%$ while in the text file reached $63.10 \%$, table 1 show few result from encryption and compression.

Table 1 shows the results of encryption and compression of three doc file types, docx and txt, from testing by DES and LZW algorithm is good for securing data type text not for data or information containing images, $\mathrm{xml}$ information or type BLOB.

\section{Conclusion}

The combination of DES and LZW algorithm on file security can be done well on various file types, but on compression result obtained highest ratio is in text file because do not have image or XML data as in Microsoft word file, based on this test got result of combination of DES and LZW whether used transactions or communication in the form of text.

\section{References}

[1] M. Liśkiewicz, R. Reischuk, and U. Wölfel, "Security levels in steganography - Insecurity does not imply detectability," Theor. Comput. Sci., vol. 692, pp. 25-45, 2017.

[2] T. N. Jabeen, M. Chidambaram, and G. Suseendran, "Security and privacy concerned association rule mining technique for the accurate frequent pattern identification," vol. 7, no. 1.1, pp. 19-24, 2018. 
[3] W. Stallings, Network security essentials: applications and standards. 2011.

[4] A. Putera, U. Siahaan, and R. Rahim, "Dynamic Key Matrix of Hill Cipher Using Genetic Algorithm," Int. J. Secur. Its Appl., vol. 10, no. 8, pp. 173-180, Aug. 2016.

[5] R. Rahim, "128 Bit Hash of Variable Length in Short Message Service Security,” Int. J. Secur. Its Appl., vol. 11, no. 1, pp. 45-58, Jan. 2017.

[6] P. Sethi and V. Kapoor, "A Proposed Novel Architecture for Information Hiding in Image Steganography by Using Genetic Algorithm and Cryptography," in Procedia Computer Science, 2016, vol. 87, pp. 61-66.

[7] A. E. S. Kacaribu and Ratnadewi, "Multiplying cipher images on visual cryptography with ElGamal algorithm," in 2015 2nd International Conference on Information Technology, Computer, and Electrical Engineering (ICITACEE), 2015, pp. 159-162.

[8] R. I. Al-Khalid, R. A. Al-Dallah, A. M. Al-Anani, R. M. Barham, and S. I. Hajir, "A Secure Visual Cryptography Scheme Using Private Key with Invariant Share Sizes," J. Softw. Eng. Appl., vol. 10, no. 01, pp. 1-10, Jan. 2017.

[9] Ratnadewi, R. P. Adhie, Y. Hutama, A. Saleh Ahmar, and M. I. Setiawan, "Implementation Cryptography Data Encryption Standard (DES) and Triple Data Encryption Standard (3DES) Method in Communication System Based Near Field Communication (NFC)," J. Phys. Conf. Ser., vol. 954, no. 1, p. 012009, Jan. 2018

[10] H. Nurdiyanto, R. Rahim, and N. Wulan, "Symmetric Stream Cipher using Triple Transposition Key Method and Base64 Algorithm for Security Improvement," J. Phys. Conf. Ser., vol. 930, no. 1, p. 012005, Dec. 2017.

[11] D. Abdullah et al., "Super-Encryption Cryptography with IDEA and WAKE Algorithm," J. Phys. Conf. Ser., vol. 1019, no. 1, p. 012039, Jun. 2018.

[12] M. Mesran, M. Syahrizal, and R. Rahim, "Enhanced Security for Data Transaction with Public Key Schnorr Authentication and Digital Signature Protocol," ARPN J. Eng. Appl. Sci., vol. 13, no. 11, pp. 3839-3846, 2018.

[13] H. Nurdiyanto and R. Rahim, "Enhanced pixel value differencing steganography with government standard algorithm," in 2017 3rd International Conference on Science in Information Technology (ICSITech), 2017, pp. 366-371.

[14] E. Kartikadarma, T. Listyorini, and R. Rahim, “An Android mobile RC4 simulation for education," World Trans. Eng. Technol. Educ., vol. 16, no. 1, pp. 75-79, 2018.

[15] R. Rahim, "Man-in-the-middle-attack prevention using interlock protocol method," ARPN J. Eng. Appl. Sci., vol. 12, no. 22, pp. 6483-6487, 2017

[16] S. Sriadhi, R. Rahim, and A. S. Ahmar, "RC4 Algorithm Visualization for Cryptography Education," J. Phys. Conf. Ser., vol. 1028, no. 1, p. 012057, Jun. 2018.

[17] A. P. U. Siahaan, "Huffman Text Compression Technique."

[18] D. Salomon, Data Compression The Complete Reference FourthEdition, vol. 53, no. 9. Springer, 2007.

[19] D. Salomon and G. Motta, HandBook Of Data Compression. Springer.

[20] R. Rahim, M. Dahria, M. Syahril, and B. Anwar, "Combination of the Blowfish and Lempel-Ziv-Welch algorithms for text compression,” World Trans. Eng. Technol. Educ., vol. 15, no. 3, pp. 292-297, 2017.

[21] M. Mesran et al., "Combination Base64 and Hashing Variable Length for Securing Data," J. Phys. Conf. Ser., vol. 1028, p. 012056, Jun. 2018.

[22] B. Schneier, "Applied Cryptography: Protocols, Algorithms, and Source Code in C, Second Edition,” Network. pp. 623-631, 1996.

[23] R. Rahim, D. Adyaraka, S. Sallu, E. Sarimanah, and A. Hidayat, "An application data security with lempel - ziv welch and blowfish," Int. J. Eng. Technol., vol. 7, no. 2.9, pp. 71-73, 2018.

[24] D. Nofriansyah et al., "A New Image Encryption Technique Combining Hill Cipher Method, Morse Code and Least Significant Bit Algorithm," J. Phys. Conf. Ser., vol. 954, no. 1, p. 012003, 2018.

[25] H. Nurdiyanto et al., "Authentication Security in Radio Frequency Identification with IDEA Algorithm," IOP Conf. Ser. Mater. Sci. Eng., vol. 384, p. 012042, Jul. 2018.

[26] F. N. Pabokory, I. F. Astuti, and A. H. Kridalaksana, "Implementasi Kriptografi Pengamanan Data Pada Pesan Teks, Isi File Dokumen, Dan File Dokumen Menggunakan Algoritma Advanced Encryption Standard," J. Inform. Mulawarman, vol. 10, no. 1, pp. 20-31, 2015.

[27] NIST, "Data Encryption Standard," Fed. Inf. Process. Stand. Publ., 1999.

[28] D. Kaur, H. K. Verma, and R. K. Singh, "A hybrid approach of image steganography," in Proceeding - IEEE International Conference on Computing, Communication and Automation, ICCCA 2016, 2017. 